\title{
Behavioral Therapy and Virtual Reality Exposure for Public Speaking Anxiety
}

\author{
Marcela Roberta Jacyntho Zacarin ${ }^{1}$ \\ Orcid.org/0000-0001-5799-9458 \\ Elizeu Borloti ${ }^{2}$ \\ Orcid.org/0000-0002-6217-6541 \\ Verônica Bender Haydu ${ }^{*}, 1$ \\ Orcid.org/0000-0002-4522-8338
}

${ }^{1}$ Universidade Estadual de Londrina, Londrina, PR, Brasil

${ }^{2}$ Universidade Federal do Espirito Santo, Vitória, ES, Brasil

\begin{abstract}
Virtual reality (VR) has been shown to be effective in the treatment of anxiety disorders. The effects of a behavioral intervention procedure that included exposure to VR, diaphragmatic breathing, differential reinforcement, and functional analysis of behavior of participants with public speaking anxiety were investigated. The Virtua Therapy simulator with an Oculus Rift ${ }^{\circ}$ was used for VR exposure. Six university students participated in the procedure involving the following sequence of sessions: initial interview and baseline measures (3-5), intervention (6), closure (1), follow-up (2). In the baseline sessions, the participants gave a speech in a room without an audience (avatars): in the intervention sessions and follow-up they spoke in a classroom or auditorium with an audience, and verbal consequences (feedback) were provided for appropriate speech pitch and speed. Verbal and non-verbal measures of behaviors were recorded. In the intervention sessions, functional analyses of everyday public speaking situations were performed. There was statistically significant difference in the pre- and post-intervention data in the Self-Statements during Public Speaking Scale (improvement in self-evaluation) and improvement in speech quality. The conclusion was reached that the intervention procedure contributed to the reduction of anxiety.
\end{abstract}

Keywords: Public speaking anxiety, virtual reality, differential reinforcement, functional analysis, Behavior Analysis.

* Mailing address: Universidade Estadual de Londrina, Departamento de Psicologia Geral e Análise do Comportamento, Rod. Celso Garcia Cid, Km 380, Campus Universitário, Caixa Postal 10011, Londrina - PR, Brazil 86057-970. Phone/Fax:+55 43 3371.4227. E-mail: mazacarin92@gmail.com, borloti@hotmail.com and veronicahaydu@gmail.com

Support: Coordination for the Improvement of Higher. Education Personnel (CAPES). 


\section{Terapia Comportamental e Exposição por Realidade Virtual para Ansiedade de Falar em Público}

\section{Resumo}

A realidade virtual (RV) tem se mostrado eficaz no tratamento de transtornos de ansiedade. Os efeitos de um procedimento de intervenção comportamental que incluiu a exposição à $\mathrm{RV}$, a respiração diafragmática, o reforço diferencial e a análise funcional de comportamentos de participantes com ansiedade de falar em público foram investigados. O simulador Virtua Therapy com um Oculus Rift ${ }^{\circledR}$ foi usado para a exposição à RV. Seis estudantes universitárias participaram do procedimento envolvendo a seguinte sequência de sessões: entrevista inicial e medidas de linha de base (3-5), intervenção (6), encerramento (1), acompanhamento (2). Nas sessões de linha de base, as participantes faziam um discurso em uma sala sem audiência (avatares): em sessões de intervenção e follow-up, elas discursavam em sala de aula ou auditório com audiência, sendo liberadas consequências verbais (feedback) para altura e velocidade apropriadas da fala. Medidas verbais e não verbais dos comportamentos foram registradas. Nas sessões de intervenção, eram realizadas análises funcionais de situações cotidianas de falar em público. Verificouse diferença estatisticamente significativa nos dados pré e pós-intervenção na Self-Statements during Public Speaking Scale (melhora na autoavaliação) e melhora na qualidade dos discursos. Concluiu-se que o procedimento de intervenção contribuiu para a redução da ansiedade.

Palavras-chave: Ansiedade de falar em público, realidade virtual, reforço diferencial, análise funcional, Análise do Comportamento.

\section{Terapia Comportamental y Exposición por Realidad Virtual para la Ansiedad de Hablar en Público}

\section{Resumen}

La realidad virtual (RV) se ha mostrado eficaz en el tratamiento de trastornos de ansiedad. Se investigaron los efectos de un procedimiento de intervención comportamental que incluyó exposición a la RV, respiración diafragmática, refuerzo diferencial y análisis funcional de comportamientos de participantes con ansiedad de hablar en público. El simulador Virtua Therapy con un Oculus Rift ${ }^{\circledR}$ se utilizó para la exposición a la RV. Seis estudiantes universitarios participaron del procedimiento con la siguiente secuencia de sesiones: entrevista inicial y línea-de-base (3-5), intervención (6), cierre (1), follow-up (2). En las sesiones de línea-de-base, las participantes hacían un discurso en una sala sin audiencia (avatares): en las sesiones de intervención y follow-up ellas discursaban en sala de aula o auditorio con audiencia, siendo liberadas consecuencias verbales (feedback) para altura y velocidad apropiadas del discurso. Las medidas verbales y no verbales de los comportamientos se registraron. En las sesiones de intervención, se realizaron análisis funcionales de situaciones cotidianas de hablar en público. Se verificó diferencia estadísticamente significativa entre los datos pre y post-intervención en la Self-Statements durante Public Speaking Scale (mejora de la autoevaluación) y mejora en la calidad de los discursos. Se concluyó que el procedimiento de intervención contribuyó a la reducción de la ansiedad.

Palabras clave: Ansiedad de hablar en público, realidad virtual, refuerzo diferencial, análisis funcional, Análisis del Comportamiento.

Anxiety disorders such as public speaking anxiety have achieved a certain prominence in medical and psychological literature because they generate significant distress for the individual experiencing them (Tyrer, Reed, \& Crawford, 2015). Techniques of gradual exposure to the object and/or feared situation are used to treat the phobias and fears that are 
observed in these disorders. Exposure can use in vivo stimuli (in vivo exposure), imagined stimuli (imaginal exposure), interoceptive stimuli (interoceptive exposure) or image/ video or virtual stimuli (VR exposure - VRE). VRE is a relatively new technique in Brazil (cf., Botella, Fernandez-Alvarez, Guillen, GarciaPalacios, \& Banos, 2017; Prates et al., 2016), and fulfilling its potential requires additional research, particularly in terms of its integration into psychotherapeutic interventions.

Virtual reality is a computer-generated environment that combines three-dimensional visual displays, real-time computer graphics, body tracking devices, and multiple sensory channels to produce immersion. Sense of presence is one of the feelings produced during immersion, considered necessary for the occurrence of other emotions, such as anxiety and fear (Krijn, Emmelkamp, Olafsson, \& Biemond, 2004). Sense of presence is the feeling of being there in the virtual environment, which involves public and/or private responses evoked by discriminative stimuli and maintained by consequences that the environment produces (operant behavior) and public and/or private responses elicited by stimuli of the virtual environment (respondent behavior; Zacarin et al., 2017). In short, VR "refers to a computergenerated environment in which the user can perceive, feel and interact in a manner that is similar to a physical place" (Parsons, Gaggioli, \& Riva, 2017, p. 2), and for this reason, it has been proposed as an adequate tool for exposure therapy.

In Virtual Reality Exposure Therapy (VRET), the virtual environment stimuli are expected to elicit anxiety "responses similar to those that would be experienced in front of the real or imagery-based counterparts of the same stimuli" (Vanni et al., 2013, p. 1562). One of the assumptions of VRET is anxiety habituation after prolonged exposures to a fearful stimulus, without the opportunity to escape (Meyerbröker, 2014).Virtual scenarios that have interactive navigation capabilities also allow the therapist to modify the environment according to the needs of each case. Thus, the therapist can intervene directly with regard to target behavior and can shape behavior through successive approximation to the situations feared using differential reinforcement.

When compared to in vivo and imaginary exposure, VR allows: (a) high degree of control of the simulated events, (b) exposure in a safe and private environment, (c) individualised hierarchization of scenarios, (d) patient and therapist to share the exposure experience, and (e) lower drop-out rates (Rothbaum, GarciaPalacios, \& Rothbaum, 2012; Safir, Wallach, \& Bar-Zvi, 2012). For these reasons, VR has been increasingly used, particularly in the psychotherapeutic treatment of fears and phobias (e.g., Price, Mehta, Tone, \& Anderson, 2011; Safir et al., 2012), such as public speaking anxiety.

Public speaking anxiety is a specific social anxiety disorder in which the primary response is avoidance of exposure to an audience (American Psychiatric Association, 2013). University students, for example, when faced with certain situations can present avoidance, such as demonstrated by Baptista et al. (2012) in a study developed with 2319 students. In academic context, these situations generally involve assessment of performance, and the avoidance of assessments may lead to low scores, failing at school, and an increased probability of dropping out of academic activities (Oliveira \& Duarte, 2004). Evaluation of intervention procedures regarding public speaking anxiety in this population is therefore socially relevant.

Several studies (e.g., Anderson et al., 2013; Anderson, Zimand, Hodges, \& Rothbaum, 2005; Brundage \& Hancock, 2015; Safir et al., 2012; Wallach, Safir, \& Bar-Zvi, 2009) have investigated procedures that use VR exposure interventions for public speaking anxiety. Wallach et al. (2009) evaluated whether virtual reality cognitive behavior therapy (VRCBT) is an alternative to cognitive behavior therapy (CBT), because of some difficulties that arise with the exposure component during CBT, such as "lack of therapist control, patient's inability to imagine, self-flooding, loss of confidentiality 
resulting from public exposure" (p. 314). In Wallach et al. study, participants diagnosed as having public speaking anxiety were randomly assigned to CBT $(n=30)$, VRCBT $(n=28)$, and to a waiting list (WL; $n=30$ ). Those participants taking part in VRCBT and CBT, but not those on the WL, showed reduced anxiety according to four out of five anxiety outcome measures and according to subject's self-rating of anxiety measured during the behavioral task. Wallach et al. predicted that VRCBT would be superior to CBT, but the data did not support this hypothesis. However, twice as many participants dropped out of CBT compared to those having VRCBT, suggesting that "VRCBT is a more client attractive treatment" (p. 334) for people with public speaking anxiety.

In a subsequent study conducted by Anderson et al. (2013), participants diagnosed as having social anxiety disorder who identified public speaking as their primary fear were randomly assigned to three groups: Virtual reality exposure therapy (VRET; $n=30$ ), exposure group therapy (EGT; $n=39$ ), or to a waiting list (WL; $n=28$ ). Both treatments consisted of a protocol of eight sessions of anxiety management training. The treatment was as similar as possible, except for the exposure modality. Results show that "there were no differences between the active treatments on any process or outcome measure at any time, nor differences in achieving partial or full remission" (p. 751). However, similarly to Wallach et al. (2009), fewer participants dropped out of those therapies combined to VR compared to those that did not included VR.

Cognitive behavior therapy protocols including virtual reality exposure were delivered in other studies, such as Anderson et al. (2005), Herbelin, Riquier, Vexo, and Thalmann (2002), Price and Anderson (2012). However, none contained VRE to behavioral therapy (except one focused on Acceptance-Based Behavioral Treatment that used VR during a Behavioral Assessment Test; Glassman et al., 2016). Behavioral therapy generally uses functional analysis of behavior (Haynes \& O'Brien, 1990; Sturmey, 1996), such as in the study on public speaking anxiety conducted by Sampaio and
Bueno (2011), with an ABA baseline design and Behavior Records Diaries. The experimenters arranged gradual exposure and reinforcement contingencies to oral presentations in the therapist's room in front of him, and a public in vivo exposure (presentation of course completion work) with the therapist in the audience. Sampaio and Bueno concluded that the procedure was effective in reducing avoidance responses and anxiety measured by Beck Anxiety Inventory (BAI) scores.

The advantages of VR as an exposure tool, as discussed previously, and the possibility of combining this form of exposure with behavioral therapy procedures led to the formulation of the following objective for the present study: To investigate the effects of a behavioral intervention procedure that included VRE, differential reinforcement of behavior and functional analysis of behavior of participants with public speaking anxiety. To achieve this objective, verbal and nonverbal measures of public speaking anxiety were used and functional analysis of behavior in day-to-day situations was performed. A non-concurrent multiple baseline across-individuals design (Watson \& Workman, 1981) enabled control of the effect of contact with the therapeutic situation (non-punitive audience) and produced familiarization with the virtual environment. The results obtained by Herbelin et al. (2002) demonstrated that this is a relevant procedure.

\section{Method}

\section{Participants}

Six female psychology students participated, whose ages ranged between 18 and 26 years. All participants reported public speaking anxiety. The inclusion criteria were: (a) being between 18 and 60 years of age, (b) having no current or previous alcohol or other drug abuse, (c) having no psychiatric diagnosis for other disorders, and (d) not being under psychological or pharmacological treatment. Participants were randomly distributed into two groups by lot, which determined the number of baseline sessions that each would perform. 


\section{Setting and Materials}

The sessions occurred in a room of the Psychology Clinic of a public university. The virtual reality system consisted of the Virtua Therapy Simulator, developed by Oníria -LdSoftware SA. It comprised an Oculus Rift巴, a joystick, a headphone and two notebooks (a Sony Vaio with an i3 processor, 4GB of RAM and 500GB hard drive and a Lenovo ThinkPad with an i3 processor, 4GB of RAM and 500GB hard drive). For the baseline sessions, the scenario was a waiting room, comprising a room with four sofas, a TV and a table with a chair. For the intervention, the scenarios were: (a) a classroom with a blackboard, a platform, a table, a chair just in front of the platform and 12 desks that could be occupied by up to 12 avatars; and (b) an auditorium with a stage and 40 seats that could be occupied by an avatar audience. It was possible to determine the number and sex of the audience in the virtual scenarios, and how they would behave during the participant's speech (e.g., paying attention, entering or leaving the room, standing in the room, smiling, answering their cell phones etc.). The researcher could communicate with the participant in the virtual scenario by activating the notebook microphone. A biofeedback apparatus (1679 Mindfield ${ }^{\circledR}$ eSense Skin Response) and an android cell phone measured galvanic skin response (GSR) during exposure. A Samsung Duos cell phone recorded the audio of the initial interview.

The Free and Informed Consent Form approved by a Research Ethics Committee (process number 1042128) informed the participants about the study and allowed them to consent to participating in it.

\section{Instruments}

Self-Statements during Public Speaking Scale (SSPS). This is an instrument to evaluate self-statements of fear of public speaking behaviors. It was developed by Hofmann and DiBartolo (2000) and validated in Brazil by Osório, Crippa, and Loureiro (2008), which comprises two subscales, one of positive self-assessment and one of negative selfassessment (in which the score is inverted), each with five items answered on a scale of 0 to 5 - SSPS has high internal consistency, Cronbach's alpha $(\mathrm{a})=.90$.

Subjective Units of Distress Scale (SUDS). This scale enables assessment of the intensity of anxiety felt when speaking in public, developed by Wolpe (1969), which is a self-rating scale that ranges from 0 to $10(0=$ completely relaxed and $10=$ completely anxious/in a panic).

Recording Sheet. Sheet of paper used to record public speaking situations that occurred between the therapeutic sessions. This Recording sheet allowed the participant to register antecedent events to the opportunity to speak in public, the response emitted, the consequences that this response produced, and the intensity of fear felt during that opportunity, on a scale of 1 to 10 .

Semi-Structured Questionnaire. This questionnaire comprising eight questions aimed to investigate whether the criteria for participation was met.

Interview Script. This script aimed to investigate the severity and context of public speaking anxiety.

Client Satisfaction Questionnaire. This questionnaire enables the participant to assess the intervention, such as the technology used, the instruments, session duration, etc.

\section{Procedure}

Participants in Group 1 performed three baseline sessions, and Group 2 participants performed five baseline sessions. The different lengths of the baseline sessions enabled evaluation of the effect of the length of contact with the therapeutic situation. All participants, regardless of their group, participated in six intervention sessions and 1- and 3-month follow-up sessions. The participants were included successively in the study, according to their availability to participate, based on a nonconcurrent multiple baseline across-individuals design (i.e. observation sequences that are not temporally concurrent; Watson \& Workman, 
1981, p. 259). All participants completed one initial session, three or five baseline sessions, six intervention sessions, one closing session and two follow-up sessions.

Initial Session. During this session, participants' received a brief explanation of the study, underwent an assessment of their knowledge of VR, and were interviewed according to the interview script. The therapist acted as a non-punitive audience to establish the therapeutic alliance. At the end of the interview, the experimenter requested that the participant answered the SSPS. The transcribed interview data enabled identification of acquisition and maintenance variables (historical, antecedent and consequent) of fear of public speaking.

Baseline Sessions. These sessions lasted approximately $1 \mathrm{~h}$ and comprised four steps: (a) information collection, (b) instructions about exposure, (c) exposure to a public speaking scenario without without an audience (avatars), and (d) investigation about their feelings during exposure. Group 1 completed three sessions and Group 2 five sessions.

At the outset, there was a brief verbal interaction to verify participant's eating, thirst, or sleeping conditions. Subsequently, the experimenter asked whether the participant had had a public speaking opportunity during the week to ascertain whether coping behaviors had occurred. The purpose of exposure in a virtual room in the absence of avatars was to familiarize the participant with the technology and to observe public speaking behavior in the absence of an audience. Prior to exposure, the participants received the following instruction:

Today you will visit a virtual room. I would like you to walk through it and observe the items in it. Do this calmly, and do not move your head too fast. Pay attention to how the avatar reacts to the joystick commands and try to move it as best you can. After that, I will ask you to begin your speech in the room. You can move while speaking or stay in a corner of the room. During exposure, I will interact with you, just to ask about your anxiety level. However, if you do not feel alright, close your eyes and let me know. When the exposure ends, I'll let you know. After this notice, close your eyes and wait for me to assist with removal of the device. Close your eyes only if you do not feel well and when putting on and taking off the Oculus.

After giving the instructions, the experimenter helped the participant put the electrodes of the biofeedback device on their fingers. The participant was then requested to remain seated and silent for 40 seconds. If the GSR measure became unstable, the participant had to wait 20 seconds more. The participant was requested to report the level of anxiety felt at that moment on a scale of 1 to 10 (SUDS, 1 = relaxed and $10=$ very tense). The participant was assisted in putting on the Oculus Rift $\AA$ and holding the joystick, and again waited a few seconds until stabilization of GSR measure. The participant was then instructed to explore the scenario and begin his/her speech when he/she was ready.

The simulator recorded the audio of the speeches prepared by the participants. After 1 minute of exposure, the therapist enabled the audio in the simulator interface and asked the participant about her anxiety level based on SUDS, repeating this procedure every 2 minutes during exposure. At the end, the experimenter told the participant to close their eyes. When the participant took off the Oculus, the experimenter said welcome back, asked him/her about his/her anxiety level and waited until the GSR measure were stable before removing the electrodes from his/her fingers.

The experimenter conducted an investigation into the participant's virtual scenario experience. She asked the following questions: (a) What was it like visiting a virtual scenario? (b) What did you feel? (c) If you felt fear or anxiety, did you do something to reduce your fear or anxiety? This procedure was repeated in all baseline, intervention and follow-up sessions.

At the end of the last baseline session, the participant answered the SSPS, and the experimenter taught her a breathing exercise (diaphragmatic breathing), which was to be 
performed in the intervention sessions. This type of exercise was included because it is a form of teaching participants to relax speech muscles (Brundage \& Hancock, 2015). Besides that, a hierarchy of scenarios to be used in the exposure sessions was built. Participants received a recording sheet at the end of the final baseline session, to be filled out with the help of the experimenter considering the public speaking situations that the participant had encountered during the previous week. A new recording sheet was then provided, which was to be completed at home and brought to the next session (first intervention session).

Intervention Sessions. Each group completed six individual sessions, lasting approximately $1 \mathrm{~h}$ and occurring twice a week. All the sessions contained the following steps: (a) functional analysis, (b) instructions for exposure, (c) breathing exercise, (d) VRE, (e) post-exposure breathing exercise, and (f) investigation about the participant's feelings during exposure. In all sessions, the participant had to prepare a speech on a desired subject, which had to be different and longer (1 minute more) than the subject chosen in the previous session. The speeches were timed to determine whether the participant spent at least the minimum amount of time speaking. The participants were notified of the added minutes ahead of time. Exposure began with the least feared situations and ended with the most feared. Only intervention Sessions 8 and 9 (Group 1), and Sessions 10 and 11 (Group 2 ) were the same for all participants and carried out in a virtual auditorium with 30 avatars.

Functional analysis was conducted during a discussion of specific public speaking situations occurring during the week that had been recorded on the recording sheet (when specific situations had not occurred, functional analysis was conducted based on a discussion regarding anxiety and fear in general, raised in the initial session). New information regarding fear and anxiety of public speaking was collected from the specific weekly situations.

Then, the participants received the following instruction:
Today you will give the speech you prepared to an audience. Remember that your speech should last at least $x$ [speech time]. First, the biofeedback electrodes will be attached, and you will perform the previously taught breathing exercise. Then, you will be exposed to a scenario related to the fear of public speaking. You should move until you are facing the audience, and when you are ready, position yourself in the room where you want to be. When the avatars come in and settle down, you can start your speech. During exposure, you can move the avatar around the scene or keep it stationary, as you wish. At some points during exposure, I will interact with you via an avatar to ask you to state your anxiety level on a scale of 0 to 10. Aside from that, you should interact with me only if it is really necessary. Remember, if you do not feel alright, the exposure can be terminated. If the minimum speaking time has not been reached, I will ask you to continue speaking, and when you finish, you can let me know. You can stop exposure at any time if necessary.

Following the instructions, the experimenter attached the biofeedback, and asked the participant to maintain a comfortable position. After that, the participant performed the breathing exercise, and once the GSR measures were stable, the experimenter applied the SUDS.

During the speech (after every minute), the participant reported his/her anxiety level (SUDS). After exposure, the experimenter controlled the following steps: SUDS application, biofeedback electrode removal and a breathing exercise. Next, an investigation about the participant's feelings during exposure was conducted and verbal consequences (feedback) for appropriate intensity (audible tone) and speed (speaking slowly with few pauses and repetitions) were given, to differentially reinforce behavior. Finally, the participants received a new recording sheet.

Operant behaviors related to fear and anxieties of public speaking were videotaped in the baseline, intervention, and follow-up 
sessions. The experimenter and a trained observer watched these videos and recorded and classified the behaviors related to fear and anxiety of public speaking. The classification was based on the operationalization performed by Angélico, Crippa, and Loureiro (2012).

At the investigation about feelings during exposure, the following questions were asked: (a) How did you feel? (b) What was it like to give a speech to a virtual audience? (c) At what points did you feel most anxious? At the end of the session, the experimenter reported the points at which the speech was paused and/or too repetitive and asked the participant to repeat those portions of inappropriate speech pitch and speed.

Closing and Follow-up. Each participant had one individual closing session. The participants completed the SSPS again, answered the Intervention Assessment Questionnaire and participated in a brief discussion of their responses. After the closing session, each participant attended the 1- and 3-month followup sessions. In these sessions, information was collected on the day-to-day situations faced and not faced and the intensity of anxiety felt in these situations. The procedure was similar to the last VRE session. Before the breathing exercise, the participants completed the SSPS questionnaire.

\section{Results}

In the interview during the initial session, the six participants of the two groups (Group 1: P1, P2 and P3; Group 2: P4, P5, and P6) reported anxiety and fear of public speaking. $\mathrm{P} 1$ and $\mathrm{P} 5$ were unable to specify how long they had had this fear, and P2, P3, P4, and P6 said that their fear and anxiety of public speaking began at secondary school. Fear and anxiety were recurrent in oral presentation situations and in conversations with large groups, primarily with unknown people. All participants reported that their fear and anxiety of public speaking affected their routines, particularly their academic routines.

Figure 1 shows the distribution of SSPS scores obtained by participants in the initial session, at the last baseline session, in the closing session, and at the 1- and 3-month followup sessions; the higher the scores were on the positive and negative SSPS subscales, the better the self-assessment when speaking in public. Figure 1 compares the initial session with the final baseline session, indicating that the Group 1 participants ( $\mathrm{P} 1$ and $\mathrm{P} 3$ ) presented a reduction in positive and negative subscale scores; however, P2's increased scores on both scales. Both positive and negative subscale scores increased for the three Group 2 participants (P4, P5 and P6), except for P6's on the negative subscale. Comparison of the last baseline session scores and the last intervention session scores revealed that all of the participants' scores increased on both the negative and positive subscales. The participants maintained the previous values or showed a slight increase over the previous intervention session in the 1-month and 3-month follow-up sessions. Statistical analysis of the SSPS data was performed considering the six participants and the positive and negative subscale, which has shown that there was a statistically significant difference for Repeated Measures Analysis of Variance for both subscales $(\alpha=.0001)$. Post hoc tests determined which data contributed to this main effect. Tests of all pairwise comparisons for both subscale, using Tukey-Kramer Multiple Comparisons Test, revealed significant differences $(\alpha<.05)$ between: initial sessions compared to closing sessions; initial sessions compared 1-month follow-up and to 3-month follow-up; final baselines compared to closing sessions; final baselines compared 1-month follow-up and to 3-month follow-up. There were no statistically significant differences $(\alpha>.05)$ between: initial sessions compared to final baselines; closing sessions compared to 1-month and to 3-month; and 1-month follow-up compared to 3-month follow-up.

Figure 2 presents mean SUDS scores and GSR variance over the baseline sessions ( 1 to 3 - Group 1; 1 to 5 - Group 2), intervention sessions (4 to 9 - Group $1 ; 6$ to 11 - Group 2) and follow-up sessions (10 to 11 - Group 1; 12 


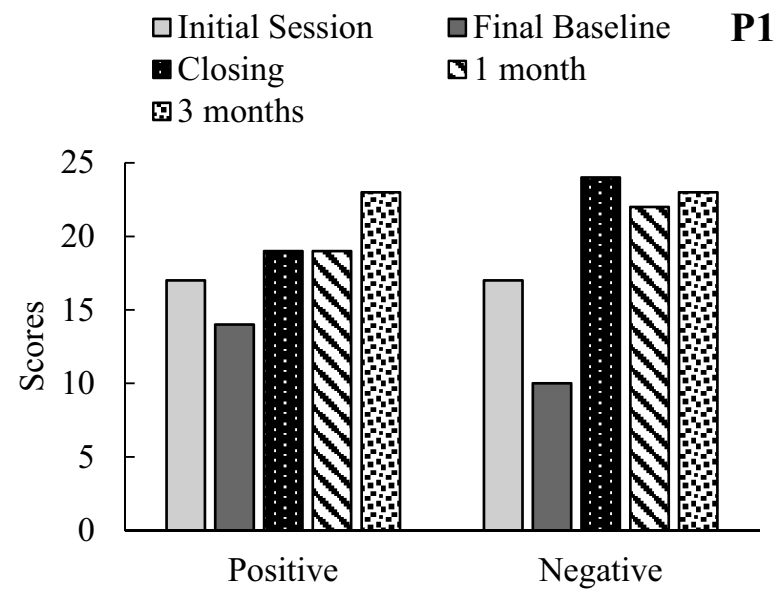

P2
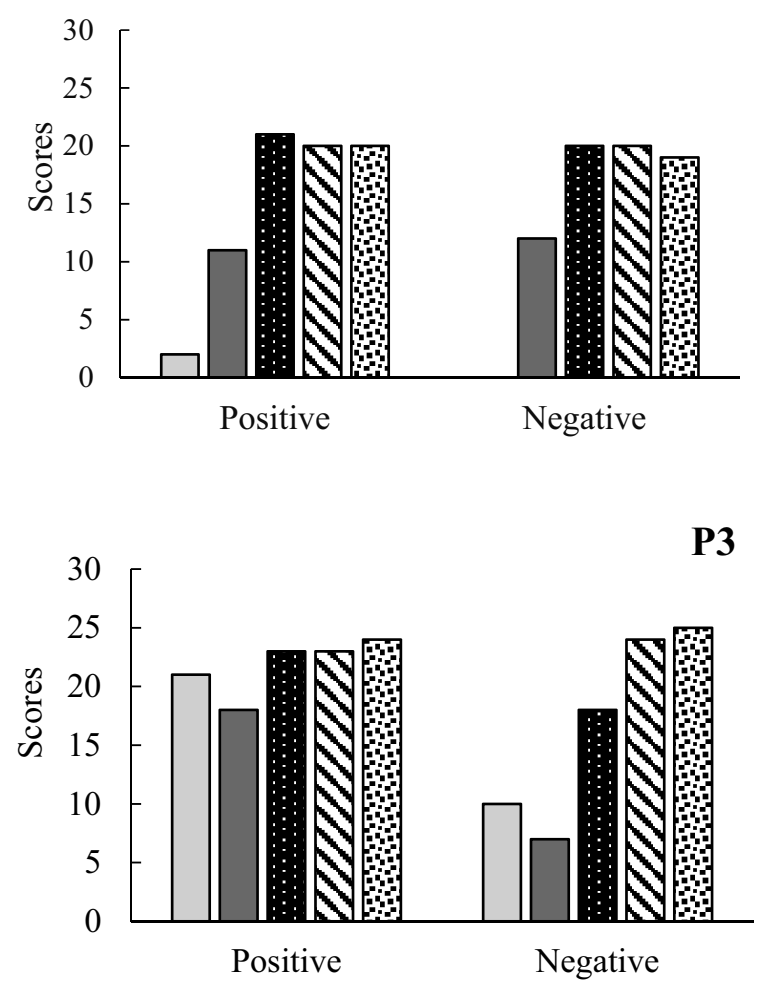

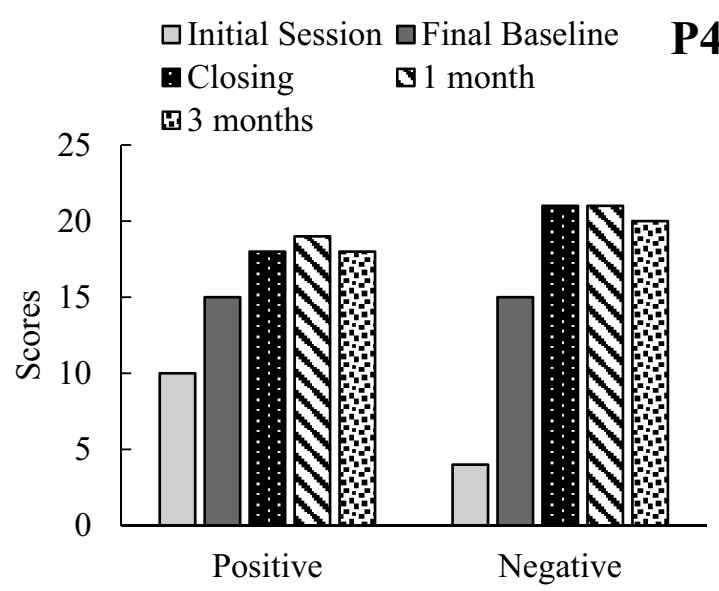

P5

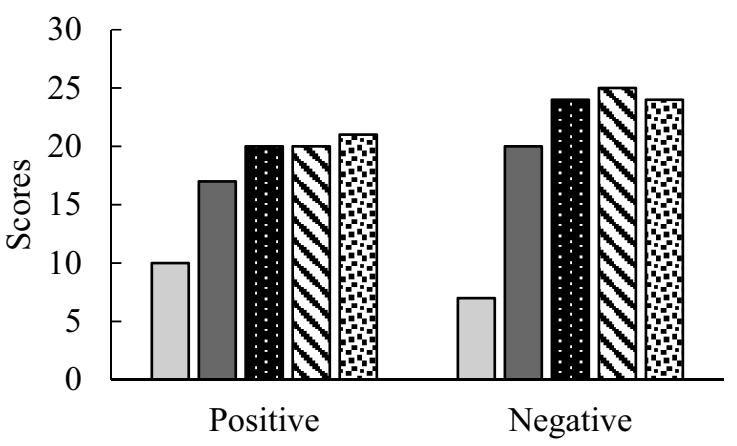

P6

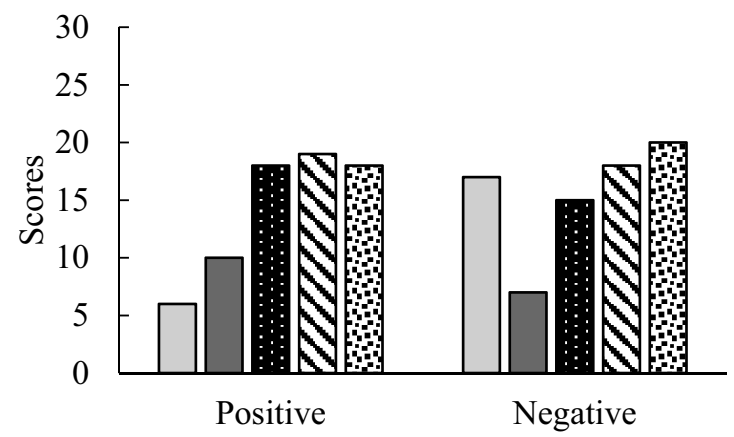

Figure 1. Positive and negative self-assessment on SSPS subscale scores in the initial session, final baseline session, closing session and 1- and 3-month follow-ups. Group 1: P1, P2 and P3; Group 2: P4, P5 and P6.

to 13 - Group 2). The anxiety scores reported (SUDS) by both groups during baseline sessions tended to be reduced, except for P6, who reported higher scores in the last three sessions than in the first two. During the intervention, the participants' SUDS scores varied: P1's scores tended to decrease, with an increase in Session 6 , in which there was a change of scenery (more people in the audience and people who were not paying attention); P2, P3, P4 and P5's scores increased in all of the sessions in which there was a change of scenery; and P6's scores increased from Session 3 to Session 10, with a reduction in Session 11. SUDS scores were lower during follow-up sessions than during the first intervention session, except for P4 and P5. In the follow-up sessions, the participants' SUDS scores varied as compared to the previous sessions: P1 and P6's scores decreased; P3's scores decreased in the 1-month follow-up 
session but increased in the 3-month followup session; P4's was the same as in the last intervention session but increased in the 3-month follow-up session; P2's scores increased in the 1-month follow-up session but decreased again in the 3-month follow-up session; and P5's scores increased and returned to the levels recorded at the baseline interventions. GSR data also varied among participants: P1's GSR variance decreased in each baseline session; $\mathrm{P} 2$ and P3's increased, and the variance of the other participants varied. In the intervention sessions,

Baseline Intervention Follow-up
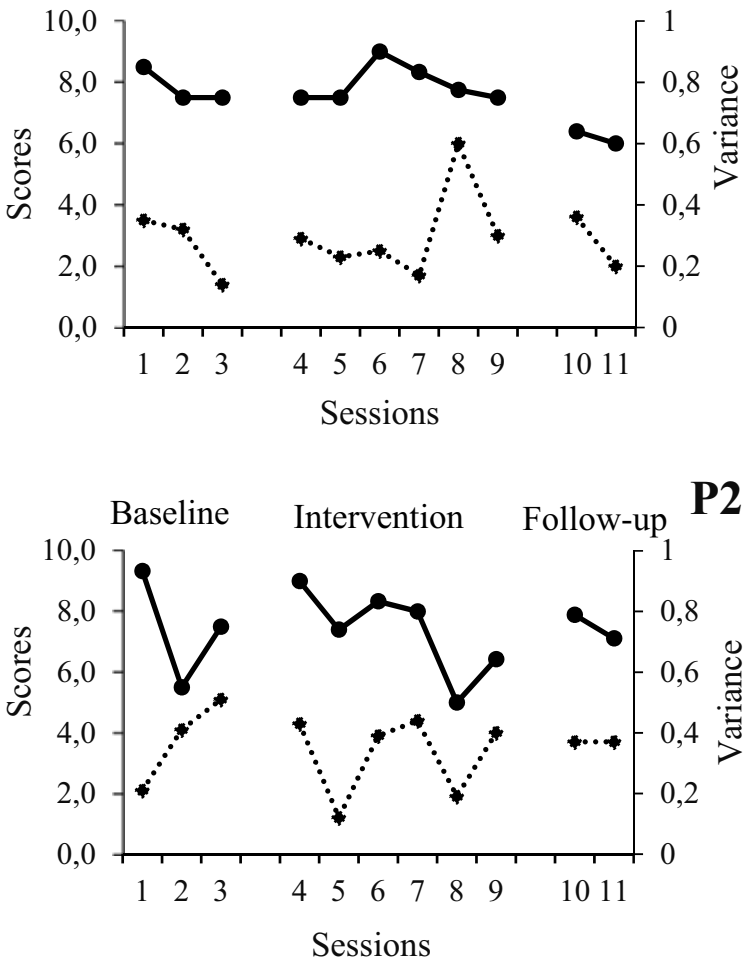

P2

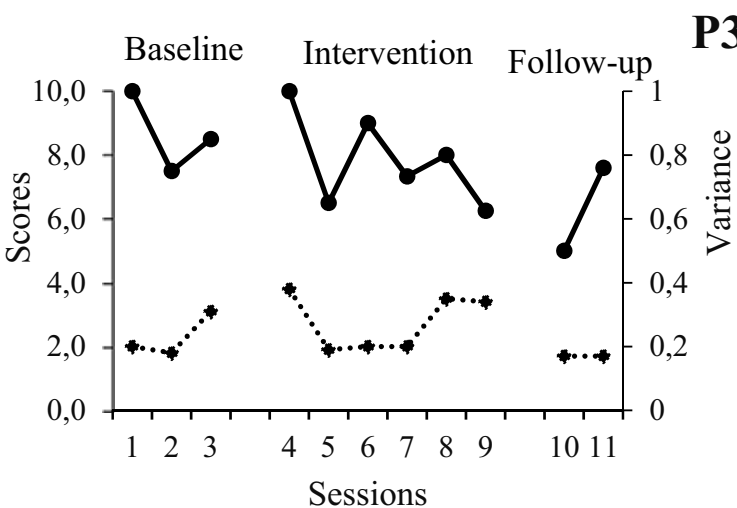

participants presented greater GSR variance in sessions in which scenario changed - Session 4 (P2 and P3), Session 6 (P2), Session 8 (P4 and P6), Session 8 (P1) and Session 10 (P6). The participants' GSR variance decreased in the 1- and 3-month follow-up sessions compared with the last intervention session, except for P1 (Session 10) and P6 (Sessions 12 and 13). Statistical analysis of correlation (Spearman Rank Correlation) between SUDS and GSR data of each participant was not significant $(p>.05)$.
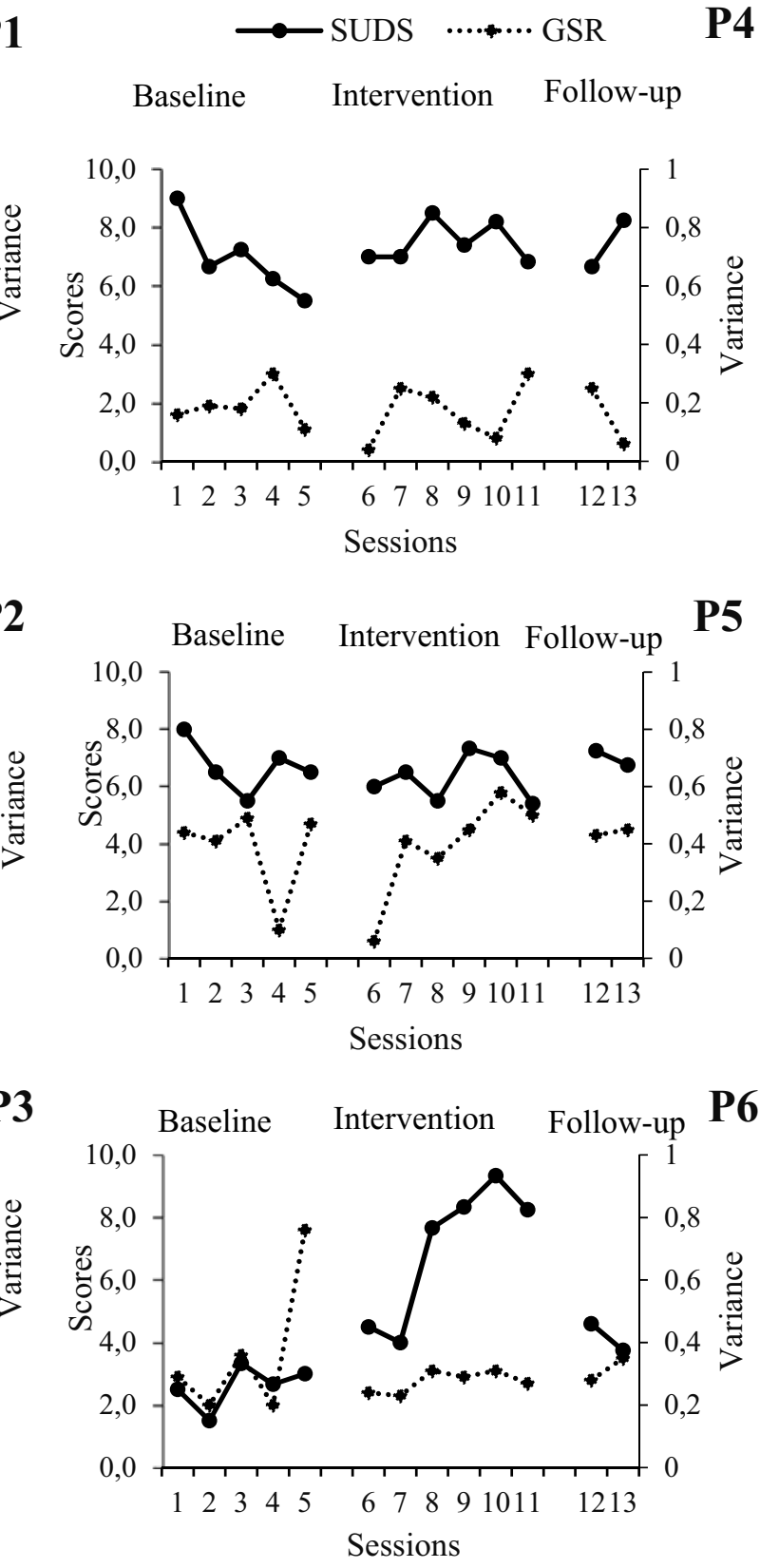

Figure 2. Mean SUDS scores and GSR variance during the baseline, intervention and 1- and 3-month follow-up sessions. Group 1: P1, P2 and P3; Group 2: P4, P5 and P6. 
Figure 3 presents the frequencies of the operant behaviors recorded while the participants were speaking. The maximum speech repetition frequency presented was two per session, with a reduction as the intervention sessions progressed. Statistical analysis (Friedman Test) of the differences between speech repetition frequency in three conditions was significant $(p=.0055)$. Tests of all pairwise comparisons, using Dunn's Multiple Comparisons Test, show significant difference $(\alpha<.05)$ between baseline sessions and follow-up sessions. There were no significant differences between baseline sessions and intervention, and intervention and follow-up $(\alpha>$.05). Silence intervals were more frequent in the first baseline session and tended to decrease during these sessions in the cases of P1, P2, P3 and $\mathrm{P} 4$ (Figure 3 ). There was a small variation in
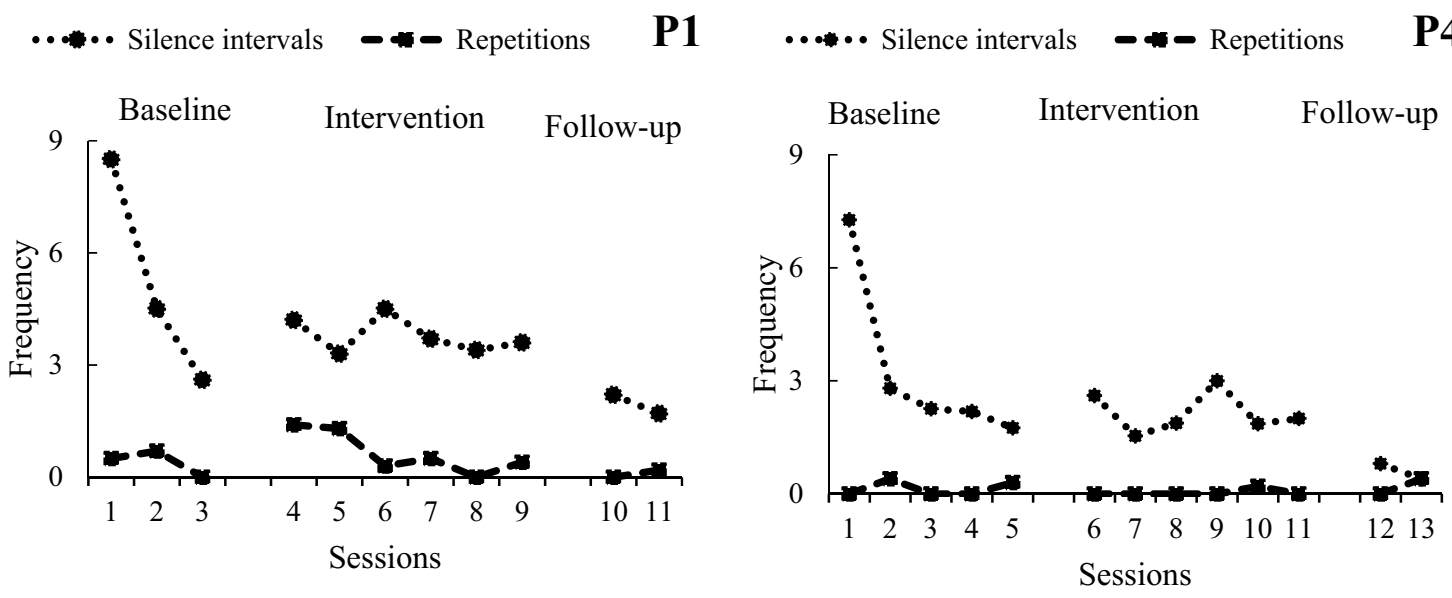

P2
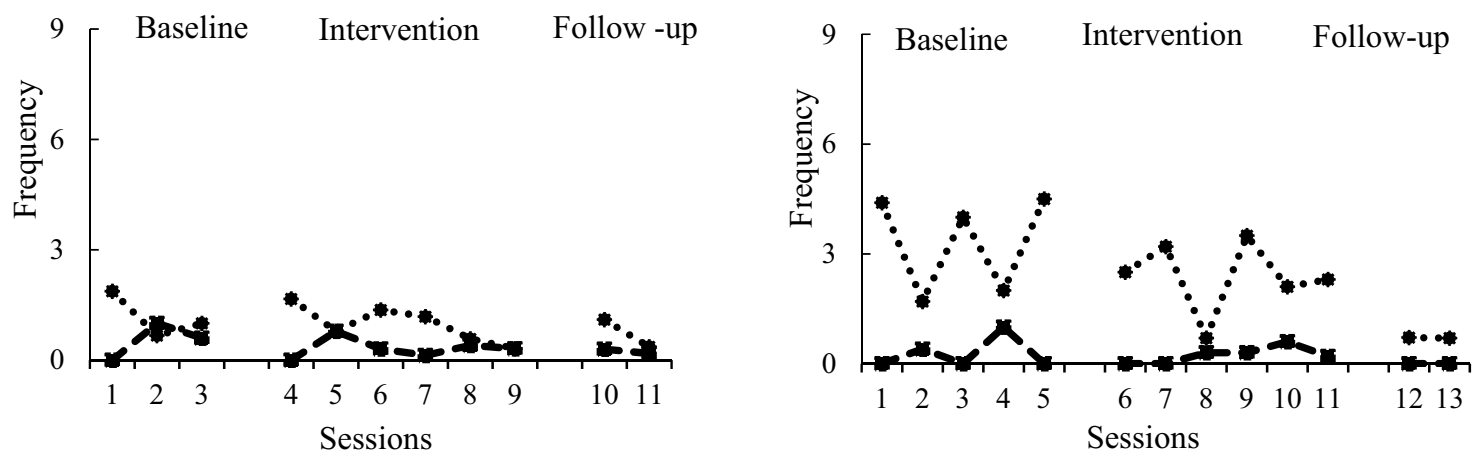

P3

P6
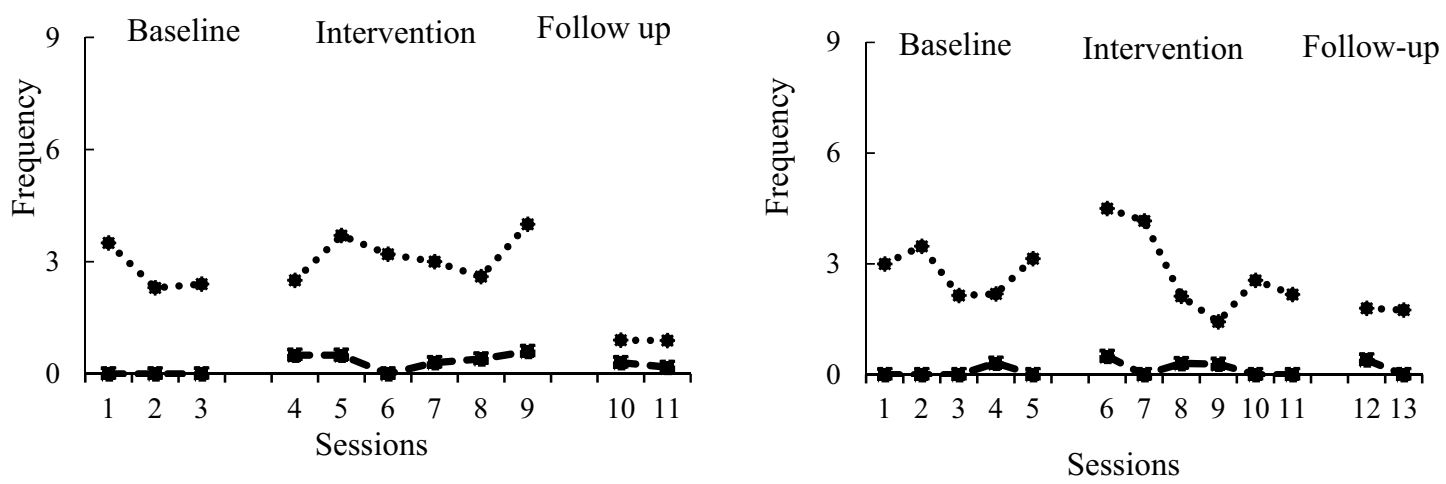

Figure 3. Frequency of talks with silence interval (pauses) and repetitions during the baseline, intervention and 1- and 3-month follow-up sessions. Group 1: P1, P2 and P3; Group 2: P4, P5 and P6. 
the frequency of participants' pauses during the intervention sessions, and there was no variation related to scenario changes. With the exception of $\mathrm{P} 2$, participants showed a reduction in pause frequency in the follow-up sessions compared with the last intervention session. There was no significant differences in pause frequency (Friedman Test) when comparing the three conditions $(\alpha=.9563)$. The frequency of silence intervals was well below the frequency of speech repetition, with no particular trend; however, in sessions in which there was a change in scenery, the frequency of such behavior increased in some cases, such as in Session 6 (P1), Session 9 (P3) and Session 6 and 7 (P6).

With regard to the public speaking opportunities noted on the recording sheets provided in the last baseline session, only P1 and P2 reported coming across a speaking situation (see Figure 4). During the intervention phase, P4, P5 and P6 faced all situations, including the follow-up phase, except P5, who did not have the opportunity to do so at the follow-up phase. P1 and P2 faced most situations at the intervention phase, whilst P3 faced none of them in the intervention phase, but did do so at the 3-month follow-up phase.

In addition to the data presented in Figure 4 , the participants reported feeling very anxious regarding public speaking situations in the first sessions; as the intervention progressed, they reported feeling less anxious and calmer when engaging in public speaking. At the 1-month follow-up, P3 reported that it remained difficult to face public speaking situations, but this changed at the 3-month follow-up session, in which P3 reported having presented a seminar and reported feeling less anxious than she would have been at the beginning of the intervention. The situations not faced by $\mathrm{P} 2$ referred to the classes in which she had questions that were clarified by questions asked by classmates. The situation that P1 did not face was also in a class; when a teacher asked someone to discuss a task taught by her in a previous class, another student spoke first; and so P1 remained silent. Overall, all participants reported more anxiety before the situation occurred; however, facing these situations was less aversive than the participants had imagined.

Regarding the Intervention Assessment Questionnaire, there were no suggestions with regard to a change in procedure, such as session time or instruments and techniques used. The only suggestion made by the participants related to the simulator: Namely, that graphic quality could be improved. P1, P2 and P4 stated that the sessions helped them realize that their speech was not as bad as they had thought and that they felt more confident speaking in public. Those participants reported feeling present and anxious in the virtual scene, and the Oculus Rift ${ }^{\circledR}$ contributed greatly in that regard. P4, P5 and P6 reported that the therapy helped them to discriminate some of the variables that maintained their public speaking behavior and that at that moment, they felt calmer about facing such situations. $\mathrm{P} 3$ reported that speaking in public remained difficult although if she must speak in public, she will do so in a calmer manner. She stated that she was not as worried about the speech going a little differently from how she had planned and that if she were to forget her speech, instead of accelerating to the end of the speech, she would now take a deep breath and continue from where she left off.

In the follow-up sessions, all participants reported feeling less anxious in public speaking situations. P2, P4, and P5 reported using the diaphragmatic breathing technique extensively to feel less anxious during presentations. P1 and P2 reported worrying less about other people's judgements; P3 said that she no longer thought her speeches were bad, as she had thought before; P4 reported that she experienced less need to control everything around her and was more accepting when she lost control of the situation; P5 said she was observing more things around her, which positively affected her relationships with other people; and P6 reported that she was speaking more slowly and observing herself more during public speaking situations. 

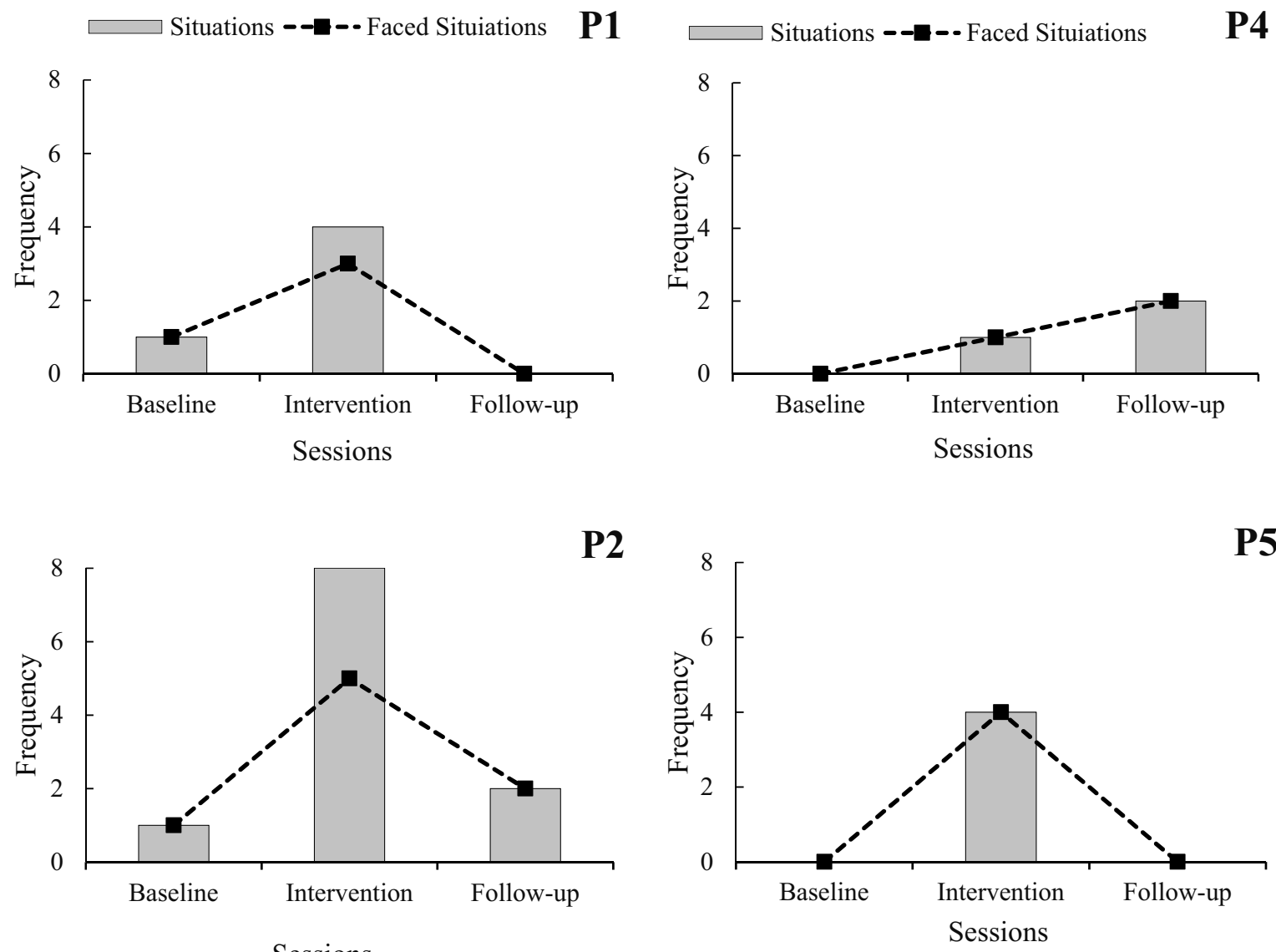

Sessions
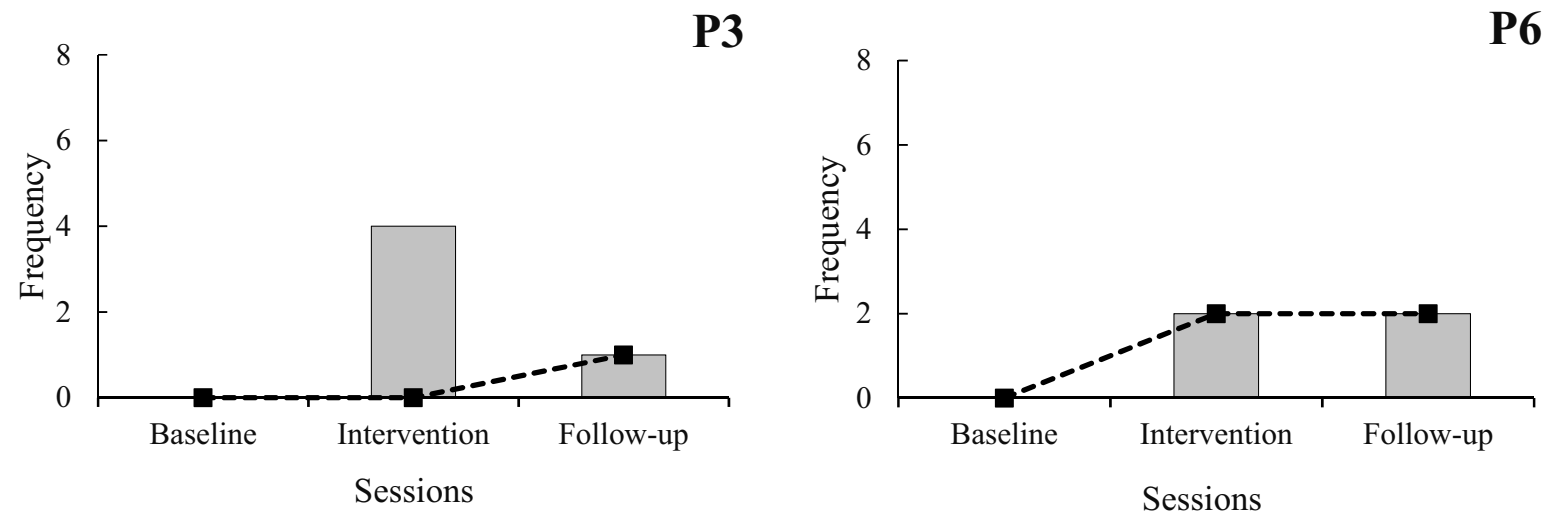

Figure 4. Distribution of public speaking opportunities (situations) and frequency of times participants faced public speaking situations, based on records provided in the last baseline session, in the intervention sessions and in the 1-month and 3-month follow-up sessions.

Group 1: P1, P2 and P3; Group 2: P4, P5 and P6.

\section{Discussion}

The objective of this study was to investigate the effects of a behavioral intervention procedure that included VRE, differential reinforcement of behavior and functional analysis of events experienced in day-to-day situations. During VRE, participants addressed an audience of avatars in a classroom setting and in an auditorium. The public speaking situation was simulated and the reactions of avatars were random, even so participants reported feeling anxiety, and a therapeutic effect was verified, as has been observed in previous studies (e.g., Anderson et al., 2005, 2013; Safir et al., 2012; Wallach et al., 2009). 
SSPS scores increased between the initial session and the final sessions (closing and follow-up), and between the last baseline session and the final sessions (closing and follow-up) in all cases. This was evidenced by better selfassessment of positive public speaking aspects (positive scale), such as "Instead of worrying I could concentrate on what I wanted to say", and better self-assessment in relation to negative aspects (negative scale), such as "A failure in this situation would be more proof of my incapacity". Some hypotheses regarding these results are as follows. Firstly, we suggest that discriminative responses of discourse quality were evoked, as was observed in studies about competing response training and awareness training (e.g., Spieler \& Miltenberger, 2017), and secondly, conditions were established to eliminate punishment effects by the presence of a non-punitive audience, represented by the therapist (Skinner, 1953). In addition, the relation between escape/avoidance responses and their consequences were discriminated due to the functional analysis of behaviors performed in day-to-day situations. Thus, VRE provided experiences that contributed to the establishment of changes in verbal repertoire, stimulus control, and changes in anxiety and avoidance responses. Studies of the literature on VRE showed similar results (e.g., Anderson et al., 2005; Villani et al., 2016; Wallach et al., 2009) and in Sampaio and Bueno's study (2011) in which participants spoke in front of the therapist before facing an audience in an academic assessment situation at the end of the therapy.

An important result to consider was the increase in SSPS scale scores in the baseline sessions of one participant in Group 1, who took part in fewer baseline sessions, and in the three Group 2 participants, who took part in more baseline sessions. These data suggest that the baseline sessions may have had a therapeutic effect even though exposure occurred in a scenario without avatars (an audience). Future research should investigate this possibility, for example, performing the same procedure with baseline recordings in the absence of giving a speech.
In the closing session, participants reported feeling less anxious regarding public speaking; in follow-up sessions, P1, P3, P4, and P5 reported facing public speaking situations more easily because of having participated in the study. Nonetheless, SUDS scores did not reduce significantly in the VRE sessions when compared to the baseline sessions. This finding can be explained by the fact that the VRE sessions contained scenes with more stimuli of the type the participants feared.

Results related to operant behaviors' (pause and repetition) show that more appropriate forms of speech increased in frequency during the intervention sessions, characterizing the verbal consequences (feedback) as reinforcements, as defined by Skinner (1953). In addition, participants reported that feedback allowed them to improve their speech and that this contributed to reducing anxiety.

Regarding coping behavior (approximation) with public speaking situations occurring outside of the sessions (data obtained from the recording sheets), with the exception of $\mathrm{P} 3$, nearly all situations were faced, which confirms the study's external validity, according to the criteria established by Del Prette and Del Prette (2008). In the classroom situations not faced by $\mathrm{P} 1$ and $\mathrm{P} 2$, the participants reported that other classmates were quicker to ask the teacher questions, which led to non-confrontation. In studies with VR exposure to address public speaking anxiety, such as Wallach et al. (2009), a reduction occurred in avoidance behaviors of public speaking situations. However, this verification is based on the Liebowitz Scale, which only provides information regarding whether the participant would or would not avoid a particular situation. According to the participants, functional analysis of the recording sheet data primarily helped them identify the consequences of avoidance and escape responses of public speaking situations, thus helping them to understand the variables that maintained these responses.

This research had some limitations. One was the number of participants and the fact that only female students participated, which 
restricts the possibility of generalization of the results. The fact that the therapist who conducted the sessions was aware of the goals of the study is another limitation that could be controlled in future studies. In addition, the greatest changes occurred in the operant measures instead of the respondent measures. One hypothesis to consider is that GSR variance in the sessions was not sensitive enough to detect changes, besides the fact that operant behaviors are the focus of functional analysis. Furthermore, participants commented that in some sessions they felt less presence in the virtual environment because of the graphic quality of the avatars' expressions and their unrealistic movements, these being emotions that may have reduced the GSR variance. Despite the need for such adjustments (suggestion with which the Virtua Therapy developer agreed), the technology proved to be effective in producing anxiety responses and contributing to reduction of the intensity of these response components. Participants also showed good acceptance of exposure through VR, confirming one of the many advantages pointed out by Safir et al. (2012).

Three main conclusions can be drawn from the results. Firstly, that breathing exercises, functional analysis, and differential reinforcement procedures combined with gradual exposure to VR contributed to reducing public speaking anxiety and increased coping behaviors, both in the virtual and non-virtual contexts. Secondly, the multiple baseline design allowed us to observe a reduction in the operant behaviors of pauses and repetitions after the intervention and allowed us to identify that longer baseline periods produce therapeutic effects. Thirdly, VR is a technological resource that can be combined with behavioral therapy and eventually improve it. We suggest that future studies utilize this resource in conjunction with other intervention strategies such as Acceptance and Commitment Therapy or Dialectical Behavioral Therapy, using the possibilities offered by VR to assess such intervention procedures.

\section{References}

American Psychiatric Association. (2013). Diagnostic and statistical manual of mental disorders (5th ed.). Washington, DC: Author.

Anderson, P. L., Price, M., Edwards, S. M., Obasaju, M. A., Schmertz, S. K., Zimand, E., \& Calamaras, M. R. (2013). Virtual reality exposure therapy for social anxiety disorder: A randomized controlled trial. Journal of Consulting and Clinical Psychology, 81, 751-760. doi: 10.1037/ a0033559

Anderson, P. L., Zimand, E., Hodges, L. F., \& Rothbaum, B. O. (2005). Cognitive behavioural therapy for public speaking anxiety using virtual reality for exposure. Depression and Anxiety, 22(3), 156-158. doi: 10.1002/da.20090

Angélico, A. P., Crippa, J. A. S., \& Loureiro, S. (2012). Transtorno de ansiedade social e habilidades sociais de falar em público: Estudo experimental. Estudos e Pesquisa em Psicologia, 12(1), 10-35. doi: 10.12957/epp.2012.8302

Baptista, C. A., Loureiro, S. R., Osório, F. L., Zuardi, A. W., Magalhães, P. V., Kapczinski, F., ...Crippa, J. A. (2012). Social phobia in Brazilian university students: Prevalence, underrecognition and academic impairment in women. Journal of Affective Disorders 136(3), 857-861. doi: 10.1016/j.jad.2011.09.022

Botella, C., Fernandez-Alvarez, J., Guillen, V., Garcia-Palacios, A., \& Banos, R. (2017). Recent progress in virtual reality exposure therapy for phobias: A systematic review. Current Psychiatry Reports, 19(7), 42. doi: 10.1007/ s11920-017-0788-4

Brundage, S. B., \& Hancock, A. B. (2015). Real enough: Using virtual public speaking environments to evoke feelings and behaviors targeted in stuttering assessment and treatment. American Journal of Speech-Language Pathology, 24, 139-149. doi: 10.1044/2014 AJSLP-14-0087

Del Prette, Z. A. P., \& Del Prette, A. (2008). A significância clínica e mudança confiável: A efetividade das intervenções em Psicologia. Psicologia: Teoria e Pesquisa, 24, 497-506. doi: 10.1590/S0102-37722008000400013

Glassman, L. H., Forman, E. M., Herbert, J. D., Bradley, L. E., Foster, E. E., Izzetoglu, M., \& Ruocco, A. C. (2016.) The effects of a brief 
acceptance-based behavioral treatment versus traditional cognitive-behavioral treatment for public speaking anxiety: An exploratory trial examining differential effects on performance and neurophysiology. Behavior Modification, 40, 748-776. doi: 10.1177/0145445516629939

Haynes, S. N., \& O’Brien, W. O. (1990). Functional analysis in behavior therapy. Clinical Psychology Review, 10, 649-668. doi: 10.1016/02727358(90)90074-K

Herbelin, B., Riquier, F., Vexo, F., \& Thalmann, D. (2002). Virtual reality in cognitive behavioral therapy: A preliminary study on social anxiety disorder. In 8th International Conference on Virtual Systems and Multimedia, VSMM2002 (pp. 1-10). Gyeongju, Korea.

Hofmann, S. G., \& DiBartolo P. M. (2000). An instrument to assess self-statements during public speaking: Scale development and preliminary psychometric properties. Behavior Therapy, 31(3), 499-515. doi: 10.1016/S00057894(00)80027-1

Krijn, M., Emmelkamp, P. M. G., Olafsson, R. P., \& Biemond, R. (2004). Virtual reality exposure therapy of anxiety disorders: A review. Clinical Psychology Review, 24, 259-281. doi: 10.1016/j. cpr.2004.04.001

Meyerbröker, K. (2014). Virtual Reality Exposure Therapy. In P. Emmelkamp \& T. Ehring (Eds.), The Wiley Handbook of Anxiety Disorders. Chichester, UK: John Wiley \& Sons. doi: 10.1002/9781118775349.ch63

Oliveira, M. A., \& Duarte, A. M. M. (2004). Controle de respostas de ansiedade em universitários em situações de exposições orais. Revista Brasileira de Terapia Comportamental Cognitiva, 6(2), 183-200. Retrieved from http:// pepsic.bvsalud.org/scielo.php? script $=$ sci arttext\&pid=S1517-55452004000200005

Osório, F. L., Crippa, J. A. C., \& Loureiro, S. N. (2008). Escala para Auto-Avaliação ao Falar em Público (SSPS): Adaptação transcultural e consistência interna da versão brasileira. Revista de Psiquiatria Clínica, 35, 207-211. doi: 10.1590/S0101-60832008000600001

Parsons, T. D., Gaggioli, A., \& Riva, G. (2017). Virtual reality for research in social neuroscience. Brain Sciences, 7(4), 42. doi: 10.3390/brainsci7040042

Prates, P. F., Pacheco, A. O., Santos, B. S., Silva, R. N., Ferraz, R. C., \& Vasconcellos, S. J.
L. (2016). Realidade virtual nas técnicas da terapia cognitivo-comportamental: Transtornos de traumas, ansiedade e depressão. Estudos e Pesquisas em Psicologia, 16, 624-643. Retrieved from http://www.e-publicacoes.uerj.br/index. php/revispsi/article/view/29352/20704

Price, M., \& Anderson, P. L. (2012). Outcome expectancy as a predictor of treatment response in cognitive behavioral therapy for public speaking fears within social anxiety disorder. Psychotherapy (Chicago), 49, 173-199. doi: 10.1037/a0024734

Price, M., Mehta, N., Tone, E. B., \& Anderson, P. L. (2011). Does engagement with exposure yield better outcomes? Components of presence as a predictor of treatment response for virtual reality exposure therapy for social phobia. Journal of Anxiety Disorders, 25, 763-770. doi: 10.1016/j. janxdis.2011.03.004

Rothbaum, B. O., Garcia-Palacios, A., \& Rothbaum, A. O. (2012). Treating anxiety disorders with virtual reality exposure therapy. Revista de Psiquiatría y Salud Mental, 5, 67-70. doi: 10.1016/j.rpsmen.2011.05.003

Safir, M. P., Wallach, H. S., \& Bar-Zvi, M. (2012). Virtual reality cognitive-behavior therapy for public speaking anxiety: One-year followup. Behavior Modification, 36, 235-246. doi: 10.1177/0145445511429999

Sampaio, N. S. de P., \& Bueno, G. N. (2011). Manejo da fobia à exposição oral: Estratégias comportamentais como agentes de controle. In C. V. B. B. Pessôa, C. E. Costa, \& M. F. Benvenuti (Eds.), Comportamento em Foco (Vol. 1, pp. 583-598). São Paulo, SP: Associação Brasileira de Psicologia e Medicina Comportamental. Retrieved from http://abpmc.org.br/arquivos/ publicacoes/14051224948bfcea692.pdf

Skinner, B. F. (1953). Science and, human behavior. New York: Free.

Spieler, C., \& Miltenberger, R. (2017). Using awareness training to decrease nervous habits during public speaking. Journal of Applied Behavior Analysis, 50, 38-47. doi: 10.1002/ jaba.362

Sturmey, P. (1996). Functional analysis in clinical psychology. Chichester, UK: John Wiley \& Sons.

Vanni, F., Conversano, C., Del Debbio, A., Landi, P., Carlini, M., Fanciullacci, C., \& Dell'Osso, 
L. (2013). A survey on virtual environment applications to fear of public speaking. European Review for Medical and Pharmacological Sciences, 17, 1561-1568. Retrieved from http:// www.europeanreview.org/wp/wp-content/ uploads/1561-1568.pdf

Villani, D., Rotasperti, C., Cipresso, P., Triberti, S., Carissoli, C., \& Riva, G. (2016). Assessing the emotional state of job applicants through a virtual reality simulation: A psycho-physiological study. In K. Giokas, L. Bokor, \& F. Hopfgartner (Eds.), eHealth 360Â: International Summit on eHealth (pp. 119-126). Budapest, Hungary: Springer International.

Tyrer, P., Reed, G. M., \& Crawford, M. J. (2015). Classification, assessment, prevalence, and effect of personality disorder. The Lancet, 385, 717-726. doi: 10.1016/S0140-6736(14)61995-4

Wallach, H. S., Safir, M., \& Bar-Zvi, M. (2009). Virtual reality cognitive behavior therapy for public speaking anxiety: A randomized clinical trial. Behavior Modification, 33, 314-333. doi: $10.1177 / 0145445509331926$

Watson, P. J., \& Workman, E. A. (1981). The nonconcurrent multiple baseline across-individuals design: An extension of the traditional multiple baseline design. Journal of Behavior Therapy and Experimental Psychiatry, 12, 257-259. doi: 10.1016/0005-7916(81)90055-0

Wolpe, J. (1969). The Practice of Behavior Therapy. New York: Pergamon.

Zacarin, M. R. J., Borloti, E. Santos, A., Perandré, Y. H. T., Melo, C. M., \& Haydu, V. B. (2017). Senso de presença: Uma proposta de definição sob uma perspectiva analítico-comportamental. Acta Comportamentalia, 25(2), 249-262. Retrieved from http://www.revistas.unam.mx/ index.php/acom/article/view/60157/53058

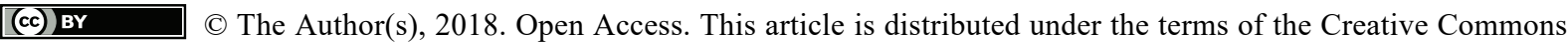
Attribution 4.0 International License (http://creativecommons.org/licenses/by/4.0/), which permits unrestricted use, distribution, and reproduction in any medium, provided you give appropriate credit to the original author(s) and the source, provide a link to the Creative Commons license, and indicate if changes were made. 